Article

\title{
Energy Sustainability of Food Stores and Supermarkets through the Installation of PV Integrated Plants
}

\author{
Alessandro Franco * (D) and Giacomo Cillari \\ Department of Energy, Systems, Territory and Constructions Engineering (DESTEC), University of Pisa, \\ Largo Lucio Lazzarino, 56122 Pisa, Italy; giacomo.cillari@phd.unipi.it \\ * Correspondence: alessandro.franco@ing.unipi.it
}

check for updates

Citation: Franco, A.; Cillari, G.

Energy Sustainability of Food Stores and Supermarkets through the Installation of PV Integrated Plants. Energies 2021, 14, 5678.

https://doi.org/10.3390/en14185678

Academic Editor:

Magdalena Hajdukiewicz

Received: 14 July 2021

Accepted: 7 September 2021

Published: 9 September 2021

Publisher's Note: MDPI stays neutral with regard to jurisdictional claims in published maps and institutional affiliations.

Copyright: (c) 2021 by the authors. Licensee MDPI, Basel, Switzerland. This article is an open access article distributed under the terms and conditions of the Creative Commons Attribution (CC BY) license (https:// creativecommons.org/licenses/by/ $4.0 /)$.

\begin{abstract}
Food stores and supermarkets are buildings, often with rather similar structures characterized by large surfaces and a single floor, that are particularly energy intensive. The energy uses associated with them are mainly electrical, in connection with air conditioning and food refrigeration. These buildings are particularly interesting for a systematic application of photovoltaic (PV) generation technology. After an analysis of the main energy consumption parameters and of the most common benchmarking approaches, standard solutions for the sizing of photovoltaic systems are proposed based on different design objectives, highlighting the potential of each solution proposed. Two specific indicators are defined for the sizing processes. The methodology is tested with reference to two different stores under the zero grid-injection restriction. The results showed how the degree of self-sufficiency for a supermarket obtained with a PV plant can be of the order of $20 \%$ in cases without storage system and can be increased over $50 \%$ and up to $70-75 \%$ but only using relevant battery storage dimensions.
\end{abstract}

Keywords: food stores; energy intensity; renewable energy systems; PV plants; sustainability

\section{Introduction}

Urban planners, engineers and decision makers who influence the built environment are increasingly asked to simultaneously develop policies aimed at enhancing sustainability and resilience-including climate change mitigation and adaptation. Even if social dimensions or economic and environmental considerations are really relevant, in a rather limited view of sustainability, two dominant measures of sustainable construction can be evinced: energy consumption and carbon emission reduction [1].

More than $40 \%$ of the total final energy consumption and about $30 \%$ of greenhouse gas (GHG) emissions are in connection with the civil and residential sector. Relevant possibilities of reducing the energy consumption lies in non-residential buildings, for public use, which are characterized by a higher energy intensity (EI) if compared to residential ones [2] and relevant emissions, $5 \%$ of the total share [3].

Considering the European countries, at least $15 \%$ of the final energy today is used in the commercial sectors; in this field, for example food stores and supermarkets are considered quite "high energy intensive" due to their relevant need for thermal comfort, refrigeration at various temperature levels from -18 to $+14{ }^{\circ} \mathrm{C}$ and lighting systems, with a relevant amount of electricity used [4,5]. The wholesale and retail trade segment represents the highest share of the final energy demand in the tertiary sector, with space conditioning and process cooling for food freezing leading the consumption; even alongside the food supply chain, the preparation and retail steps account for a high share of the energy consumption, between $30-40 \%$ [6].

The common energy saving techniques, related to the various systems installed, the building envelope and demand management represent the opportunity for this specific building category to increase the overall sustainability, in terms of both energy supply and GHG emissions. Moreover, these measures proved to have a beneficial impact on the 
community awareness about sustainability and eco-friendly technologies [7]: a corporate social responsibility strategy that enhances the brand value. Energy efficiency is, therefore, considered a strategic priority [5]. Recent data on energy consumption in the food stores monitored and collected under specific structures and climatic conditions show that the energy use intensity, expressed as energy used over floor or sales area for a whole year and acknowledged as a proper measurement parameter, even if still quite high, has been largely reduced in the last ten years. This is mainly verified in the quite large structures with a floor area higher than $700 \mathrm{~m}^{2}$, mainly in combination with energy-efficient technologies installed in all subsystems, including refrigeration systems, Heating Ventilation and Air Conditioning (HVAC) for thermal control and lighting systems [8-10].

The integration of renewable energy systems (RES) as active measures for energy production appears a reasonable step in conjunction with the aforementioned strategies. The relevant amount of electricity used in supermarkets, focused in daytime, makes it easier to move towards a net Zero Energy Building (nZEB) configuration and to pursue objectives of intelligent use of sustainable resources [11,12].

Moreover, energy system integration grows in importance requiring the services of technologies such as storage as a key enabler, both at a central level and distributed for flexible consumers. In particular, as the use of energy is in phase with the solar energy availability, the stores for the sale of food become the most interesting candidates for the installation of photovoltaic (PV) power plants, aimed at self-production of energy among the tertiary sector buildings, making it possible to avoid the problem of placing the surplus of energy produced into the electrical grid. The sector of food stores in general, including supermarkets and superstores, due to the quite high energy load and the quite large availability of surfaces, appears to be strategic in order to promote a further increase of the diffusion of Building Integrated PV (BIPV) plants.

The installation PV plants has been grown in Europe mainly in independent applications at all levels and complexities: on roofs or facades of buildings for domestic and commercial use of various size and typology. Non-programmable RES will surely become the reference source and a strategic innovative element before 2030, mainly thanks to the wider and strategic diffusion of Photovoltaic (PV) plants. In this perspective, the useful integration of these vital contributors within the buildings for the future energy transition strategy is worth investigating; the added advantage of this technology is the opportunity to site the plants everywhere, most importantly on buildings, right where the actual load is, directly contributing to the optimal use of resources.

Today, more than $600 \mathrm{GW}$ of solar PV power plants have already been installed worldwide, making solar PV the second renewable electricity source. A substantial portion of the PV installations until now have been related to the randomness of feed-in tariffs established by local governments and this caused problems to the energy systems, as evidenced by one of the authors of the present paper in $[13,14]$.

The spread of Building-integrated PV (BiPV) can represent a new stable driving force for the diffusion of PV systems: they consist of PV modules that function as part of the building envelope (curtain walls, roof panels or shingles, shading devices, skylights). BiPV systems are sometimes installed in new "showcase" buildings even before the systems are generally cost-effective.

Food stores and supermarkets represent a strategic sector in this perspective. In this case, as observed in the previous section, direct use of the energy generated is an obvious choice, hence avoiding costly conversions and energy dispatch. The investigation of proper size and design of PV systems for supermarkets proceeds to be an interesting and innovative topic, as most research focuses on the effect of envelope and system energyefficient solutions [15].

The high standardization of envelope and constructions behind stores structures mainly in the medium to high size, that include typical prefabricated materials, gives value to the use of benchmark indicators, derived from measured data in a bottom-up approach, as they can be properly scaled and adapted for future design. Through these indexes, a 
sizing analysis can take into account different strategies and configurations to maximize the share of self-consumed energy, including proper system and storage sizing, demand-side management and forecast.

The present work aims to determine possible benchmark values and related key performance indicators based on the analysis of the energy use in food retail structures, to try defining possible reference values according to the climate conditions and the size of the store for the sizing of PV systems. The investigation examines the annual energy consumption and cooling and heating demand of typical supermarket structures. Monitored data of some specific cases are then shown; case studies represent the common Italian supermarkets. After an analysis of the energy consumption parameters in the typical seasonal operating conditions, results are compared with the data of similar structures located in different countries; criteria and guidelines for the design of PV systems are developed based on different purposes on balancing energy production and use. The purpose is to validate the efficacy of reference values, based on real data, to determine the correct size of different PV system configurations and evaluating the impact of the integration of the renewable source. Considering the aforementioned aspects, the paper analyzes the perspective of active methods for energy production, consisting of the development of PV plants for reducing the carbon footprint of food retail structures and supermarkets. Starting from the extensive analysis of the energy consumption of two case studies referring to two food stores typical of Italian territory (although similar structures are largely diffused in various European countries and in the world), the paper proposes a possible sizing methodology for PV plants that have as an objective the maximization of the share of self-consumption of the energy produced. Various articles discussed the increase in self-consumption of PV plants. However, almost all the researchers have been focused on the residential sector. Considering the growing interest in reducing the energy use and carbon footprint of the commercial sector, the topic of designing solar PV plants for self-consumption in commercial buildings has been reported only in some recent papers. Allouhi in [16] have studied the optimal PV size in commercial buildings, in a high self-consumption configuration, for the hot dry climate of Morocco through a life-cycle economic/environmental evaluation, for a gross an annual electricity demand of $2.932 \mathrm{GWh}$; the optimal size found was $847 \mathrm{~kW}$ of peak power. The potential and practicability of self-consumption for an easy integration of PV in buildings, especially without other policies and benefits, is stated even in the supermarket sectors: an analysis carried out on a store in Germany with a yearly electricity consumption of $238 \mathrm{MW} \mathrm{h}$ /year showed that systems with PV peak power up to twice the peak load are economically advantageous with an optimal degree of self-consumption and self-sufficiency [17]. The present work can be inserted within this short set of research, with the specific constraint to pursue the objective of PV integration under the zero grid-injection restriction: unlike cited work, the aim is to provide general and practical guidelines for PV sizing with different configurations, directly derivable from the analysis of the consumption profile.

\section{Correlation among Energy Consumption and Size of Store in the Food Retail Sector: Energy Use Intensity}

The high repercussion of tertiary sectors on energy consumption depends on the type of building and the operation inside, that are quite different according to the category the building belongs to: office, shopping and commercial, sports, educational buildings, medical treatment and others. The market segment of the food supermarket is the most intensive in terms of energy consumption per square meter, within the buildings for commercial use [5].

Food stores and supermarket are in general rectangular base buildings, with one floor in which six different zones can be identified: in general sales, produce, dry storage, bakery, delivery area and offices. In some cases, in particular in some high size stores, each different zone is served by a specific HVAC system, while in other cases, mainly for structures with reduced floor area, one or two chillers with multiple air handling units (AHU) are used. In the literature different classifications can be identified, but in general it is clearly evidenced 
the difference in terms of sales floor area, as reported in Table 1, in which, according to the classification proposed in [5] and rearranged by the authors of the present paper, four different typologies of structure can be identified, referring to the sales floor area.

Table 1. A possible classification of food retail structures.

\begin{tabular}{cc}
\hline Store Type & Sales Floor Area \\
\hline Hypermarkets & $>6000 \mathrm{~m}^{2}$ \\
Superstores & $1500-6000 \mathrm{~m}^{2}$ \\
Supermarkets & $400-1500 \mathrm{~m}^{2}$ \\
Convenience store & $<400 \mathrm{~m}^{2}$ \\
\hline
\end{tabular}

The energy consumption of a supermarket, distributed among the different areas of the structure, is represented in major part by electricity. The composition of the pattern of distribution of the electric energy consumed by the different areas is associated with the following services: lighting, air conditioning and ventilation, cooling system, refrigeration units and miscellaneous consumption. A statistical analysis of electricity consumption permits obtaining of average values, well represented by the energy intensity. Such a value can be expressed in $\mathrm{kWh} / \mathrm{m}^{2}$ for the year and can be referred to the total area of the store or only to the sales area.

Food stores and supermarkets present a unique space conditioning challenge because of the interaction between the HVAC system and the refrigerated display cabinets: the first has to keep both high thermal comfort levels for the customers shopping experience and guarantee the necessary conditions for non-refrigerated products. In particular, the HVAC system is responsible for the highest share of the total consumption after refrigeration, based on the system configuration, the geographical location and the management. HVAC systems vary among different supermarkets [18], each one involving different layouts and components that can be arranged in several ways in various configurations. Regardless, five different processes can be considered to achieve all the air-conditioning services, namely heating, cooling, humidifying, dehumidifying and ventilation [19]. Figure 1 provides a typical layout configuration for a food store considering the HVAC system too.

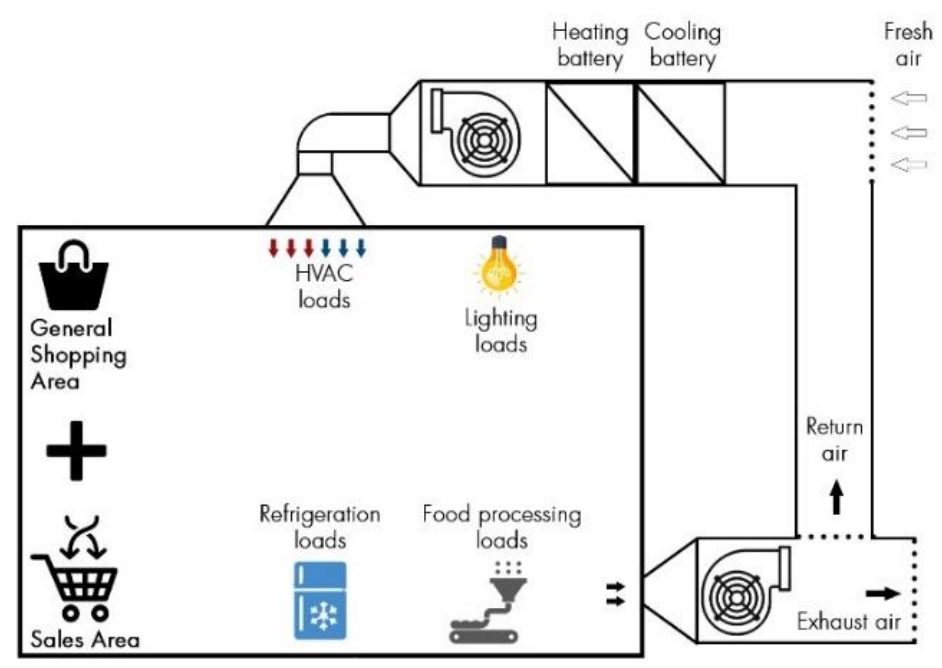

Figure 1. HVAC system operation and supermarket common loads.

The total energy used in the food store depends on business practices, store format and size, product food ratio, equipment use for in-store preservation and display, management of HVAC and lighting systems installed. Small supermarkets or convenience stores $\left(<400-500 \mathrm{~m}^{2}\right)$, mainly diffused in the urban area, show a higher energy intensity than larger superstores due to the high ratio of food against non-food products. In this scenario 
the energy consumption related to refrigeration can increase up to 50-60\%, as shown in a recent paper [10], while only $30 \%$ is correlated with HVAC operation. About 15-20\% of final energy consumption is correlated with the lighting systems and miscellaneous electricity loads. Other relevant differences can be reconnected to climatic elements. The smaller the store the highest the energy use due to the higher refrigeration equipment used [20]: the ratio of food and non-food products becomes less crucial as the total sales area increases, while the lighting share becomes more significant. The EI (Energy intensity) index or normalized EI index, in which the energy intensity is referred to a single day or to a single month, is generally adopted to measure the overall energy use of buildings of public use.

The relevance of the energy consumption of shopping malls and supermarkets among the various tertiary activities has been determined by several studies; as already mentioned, the energy intensity of the food stores or supermarkets is in general quite high with respect to different commercial stores. According to the work of Wu et al. in [4], that presented a method to evaluate the building energy consumption through specific indexes for different functional sectors in China, the food retail sector is characterized by EI values in the range between $150 \mathrm{kWh} / \mathrm{m}^{2}$.per year and $450 \mathrm{kWh} / \mathrm{m}^{2}$ per year. Sales and total floor area and supermarket energy consumption showed a good correlation: the main uncertainties of the estimation are due to the different design of structures and, mainly, by the different references for energy intensity computation. In fact, data reference difference depended on both energy stream, either based on the total energy consumption or limited to the electrical consumption, ignoring the use of gas, and the surface, being either the total floor area or the net sales floor area. Once the influence of the incidence of these uncertainties has been evaluated, a wide range of variability is perceivable in the data. Ríos Fernández and Roqueñí in a recent paper have correlated the energy intensity of the Spanish supermarkets to the floor area: the results, which represent a valid reference element for this paper, are summarized in Table 2 [8]. Those values can be considered representative of the case of Italian supermarkets too, due to close climatic conditions between the two countries, mainly considering central and southern Italy.

Table 2. A possible classification of food retail structures based on sale area and energy intensity.

\begin{tabular}{cc}
\hline Exhibition and Sale Area $\left.\mathbf{( m}^{\mathbf{2}}\right)$ & Energy Use Intensity $\left(\mathbf{k W h} / \mathbf{m}^{\mathbf{2}} \mathbf{y}\right)$ \\
\hline $400-1000$ & 600 \\
$1000-1500$ & 540 \\
$1500-2000$ & 490 \\
$2000-2500$ & 440 \\
\hline
\end{tabular}

Different authors from the UK, considering the specific problem of energy consumption of food stores and supermarkets [21,22] show an electrical energy consumption over sales floor area that is quite higher. The authors in particular identify very high values, ranging from 770 up to $1480 \mathrm{kWh} / \mathrm{m}^{2}$ per year, moving from hypermarket to convenience-size stores. Analyzing the energy use by subsystems, the authors assign 30-35\% to refrigeration, $20-25 \%$ to HVAC and about $15-20 \%$ to the lighting system [22]. Van der Sluis et al. in a similar paper [23] shows that specific energy consumption (SEC) values, in particular total energy referred to gross floor area, analyzed in different countries, in particular Germany and Canada, show energy intensity values in the range between 400 and $800 \mathrm{kWh} / \mathrm{m}^{2}$ per year (lowest from a Dutch supermarket chain and highest in Canadian stores). Even if the difference in calculation of energy intensity is taken into account, the electrical energy intensity in UK supermarkets appears to be 2.5 times as high as the value in Dutch supermarkets. As refrigeration is responsible for a large part of the energy used by stores, refrigeration capacity was considered to assess whether it correlated well with energy intensity [24,25]. The energy efficiency issue in commercial structures has been largely investigated in recent scientific and technical literature. Enhanced utilization of daylight, or a combination of natural and mechanical ventilation with improved control, improved refrigeration cabinets, 
with doors on frozen food cabinets or an acceptance of a wider range of internal temperatures as efficiency measures proved to have a wide impact on the final energy use of such structures [26]. The various efficiency measures mentioned, including HVAC system management, renovation of the lighting system with LED technology and the use of more efficient refrigeration units, as for example the systematic use of cabinet with automatic closing doors, can be important in order to determine a reduction of the EI [11,12].

The relevance of such efficiency measures is higher in smaller stores, where there is a high refrigerated food on goods ratio, typically greater than in larger stores that merchandise more non-grocery products. In general, commercial structures such as supermarkets and superstores are among the most energy-consuming subsector of the civil segment, despite the differences in the data analyzed. For this kind of structure, not only the implementation of saving measures but also the integration of active measures with the relevant introduction of energy production from renewable sources becomes particularly interesting. Some studies focused on the economy behind the installation of PV systems [27]. A study on the profitability of commercial self-consumption solar installations in the supermarkets sector led in three German supermarkets showed the profitability of these kind of systems if the costs of the PV systems decrease between EUR 200/kWh and EUR 600/kWh. Nevertheless, this study does not consider battery storage applications [28]. Other studies focused more on the environmental consequences [29]: the common conclusion is the relevance of the integration of PV systems, the particular suitability of stores, for both the magnitude and trend of the demand profile and the available surface and the profitability of high self-consumption schemes.

\section{Energy Consumption Profile, Efficiency Measure and Use of Renewable Energies}

The framework described in the previous section has focused on general, peculiar, elements of food stores and related typical consumption data for food sales with reference to the average annual data and to reference values of the average EI. The design of a PV plant, however, planned for the energy production, needs the support of the variations of the energy consumption over time. The trend is influenced by several factors: the calendar day, the number of opening hours, the customer's presence, external temperature, humidity and daylight. Following this purpose, we have monitored the consumption of two food stores. One is the typical supermarket, meant for food sale (case B), while the second is a typical hypermarket (case A), where the food store, which takes up most of the sales area, is mixed with different, smaller stores. The two stores are located in two different towns of Tuscany (central Italy). The climatic data of the coastal region of Tuscany are reported in Table 3 , in which is the average value of external temperature, the typical average solar irradiation, the relative humidity $(\mathrm{RH})$ and the wind velocity.

Table 3. Reference climatic data for central Tuscany.

\begin{tabular}{|c|c|c|c|c|c|c|c|c|c|c|c|c|c|}
\hline & Jan & Feb & Mar & Apr & May & Jun & Jul & Aug & Sept & Oct & Nov & Dec & Year \\
\hline $\mathrm{T}_{\mathrm{avg}}\left({ }^{\circ} \mathrm{C}\right)$ & 7.3 & 7.4 & 10.7 & 12.9 & 17.9 & 20.6 & 22.9 & 23.1 & 19.8 & 15.6 & 11.7 & 7.6 & 14.8 \\
\hline $\mathrm{H}_{\mathrm{d}}\left(\mathrm{kWh}\left(\mathrm{m}^{2} \mathrm{~d}\right)\right)$ & 1.6 & 2.3 & 3.3 & 4.3 & 5.9 & 6.4 & 6.8 & 5.9 & 4.4 & 2.6 & 1.9 & 1.4 & 3.9 \\
\hline Outdoor RH (\%) & 85.0 & 74.8 & 79.8 & 78.9 & 74.4 & 74.2 & 71.5 & 76.6 & 81.5 & 86.2 & 78.3 & 85.8 & 79.0 \\
\hline Wind velocity $(\mathrm{m} / \mathrm{s})$ & 1.8 & 1.5 & 1.3 & 1.6 & 1.9 & 1.6 & 1.7 & 1.3 & 1.0 & 1.4 & 1.6 & 2.1 & 1.6 \\
\hline
\end{tabular}

The specific data of the two structures are reported in Table 4. The two structures used as test cases are modern structures, equipped with all the main energy efficiency measures, both concerning the building and the various systems (HVAC, lighting and refrigeration units) and are representative of two typical modern food stores available in Italy.

Analyzing the energy consumption data measured in real operating conditions, it can be observed that in this case there is a significant variation both within the single day and in the different seasons. Since energy consumption is largely due to refrigeration, energy uses are more relevant during the summer season. Figures 2 and 3 provide the hourly trend of energy consumption for the two stores under analysis, measured in real 
operating conditions. As it is simple to observe, there exists a minimum level of energy consumption for maintaining lighting, security systems and food refrigeration during the night-time and, only in some special cases, the energy consumption drops to zero, even if the supermarket is closed, and even if such cases can be considered as outliers. In particular, in Figures 2 and 3, on the ordinate axis the total energy consumption of the store is provided during the different hours of one year (a total of 8760), provided on the abscissa axis and corresponding to the period from 1 January to 31 December.

Table 4. Main geometrical data about the two stores under analysis.

\begin{tabular}{ccc}
\hline Store & Kind of Structure & Total Gross Area $\left(\mathbf{m}^{\mathbf{2}}\right)$ \\
\hline A & Hypermarket & 16,000 \\
B & Local superstore & 4830 \\
\hline
\end{tabular}

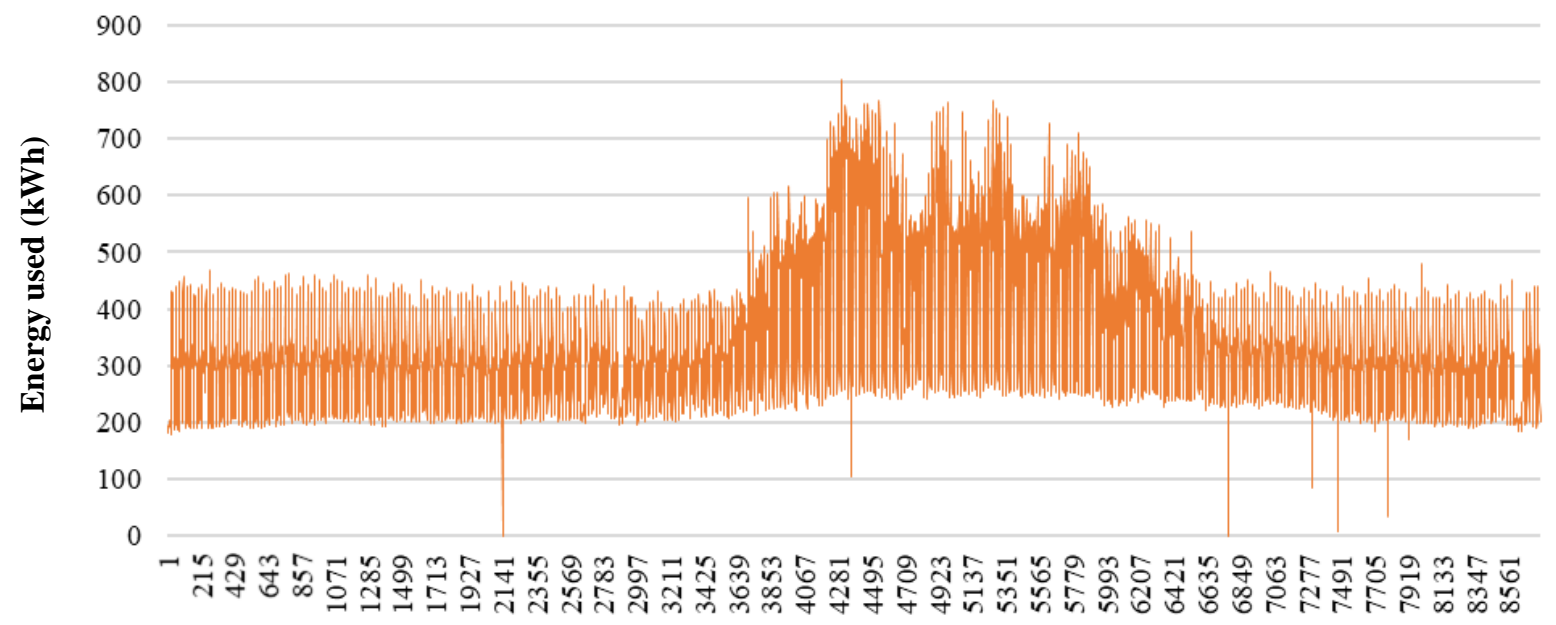

Progressive hour of the year

Figure 2. Hourly trend of energy consumption for the higher size supermarket (for Store A).

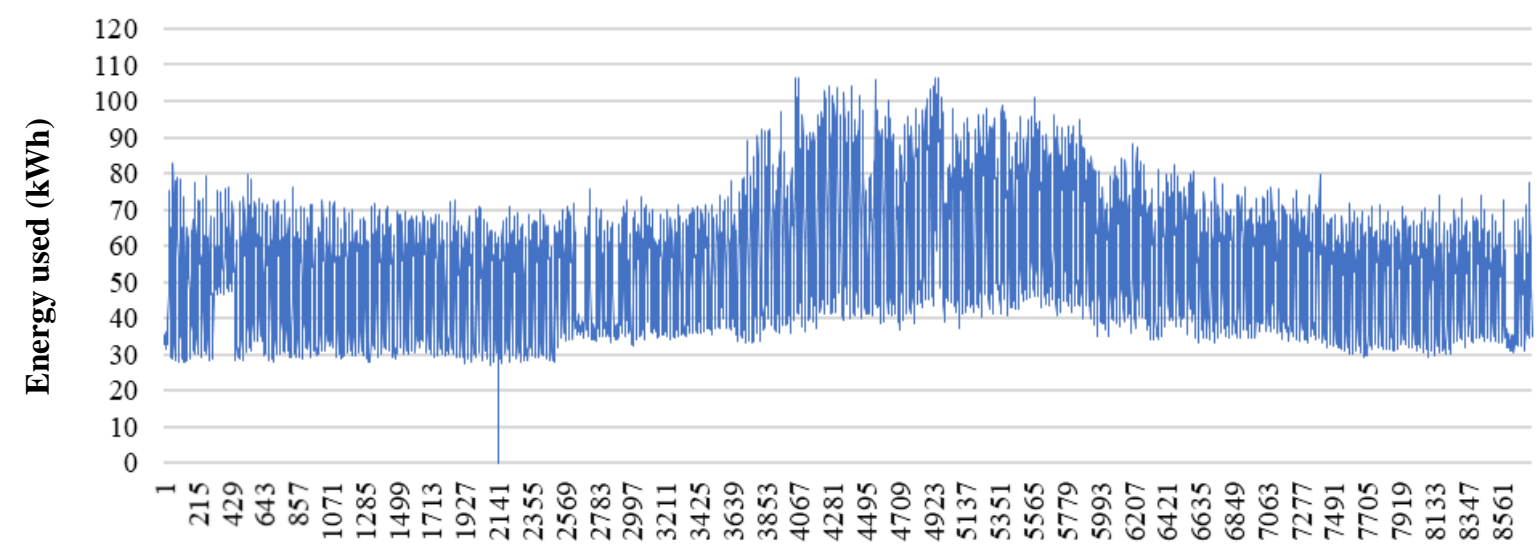

Progressive hour of the year

Figure 3. Hourly trend of energy consumption for the higher size supermarket (for Store B).

The analysis of these rough data highlights the overall range of variation but is not useful to understand the actual behavior of the supermarket and identify reference values for system sizing. The maximum hourly energy consumptions for both the stores was during summertime and it corresponded to about $800 \mathrm{kWh}$ for Store A and $100 \mathrm{kWh}$ for Store B, while the minimum values were approximately $200 \mathrm{kWh}$ for Store A and $30 \mathrm{kWh}$ 
for Store B (the minimum values were obviously observed during the night and in the cold season).

To compare the structures under investigation with the benchmarks defined in the previous section, in Figure 4 the hourly and average values of energy intensity, referred to the store surface, are provided for both the cases. Some useful data can be extracted from the daily trend; in particular, the base load, occurring during the night, when the supermarkets was closed and the value and the time of the peak of electrical demand, occurring from the late morning and the evening, depending on the different seasons: those data are of fundamental importance for the accurate design of a PV plant for energy production.

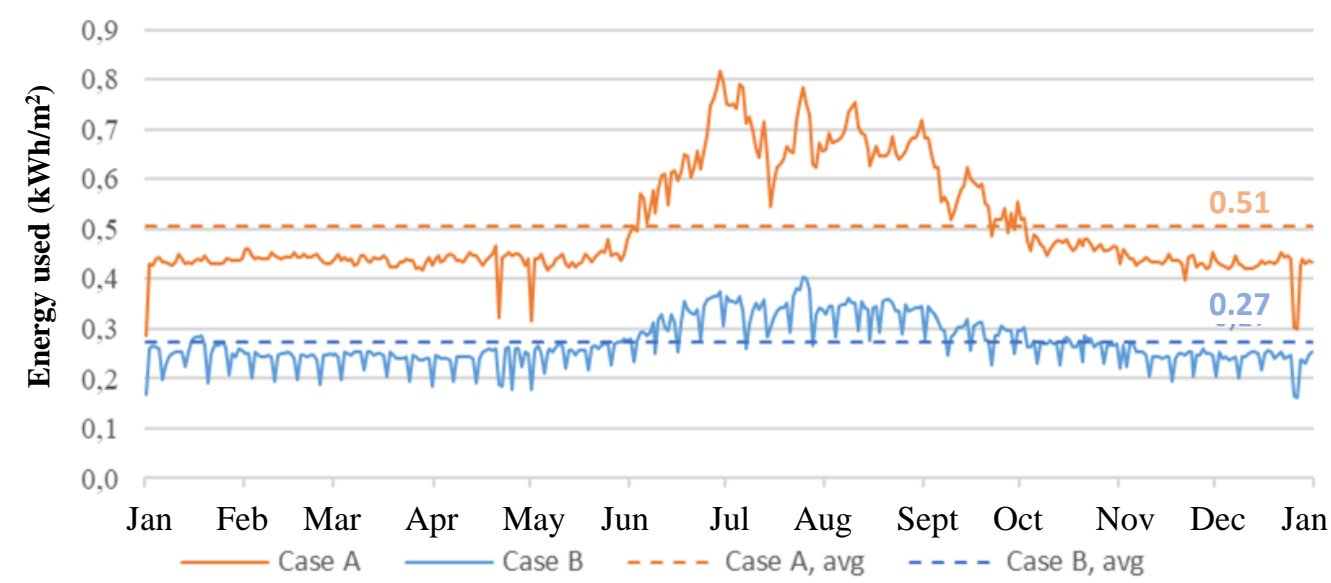

Figure 4. Specific daily energy consumption $\left(\mathrm{kWh} / \mathrm{m}^{2} \mathrm{~d}\right)$ profile for the two supermarkets under analysis.

In both the cases, Store A and Store B, a base load that is active for the $24 \mathrm{~h}$ for all the days of the year (typical days of the week, pre-holidays and holidays) can be detected: a minimum value of the hourly electrical demand of about 200-260 kWh in the first case (store A) and of 30-45 kWh in the latter one (store B) can be considered.

Those minimum values are obviously connected to refrigeration loads that keep working when the store is closed. The consistent and quite constant electricity baseload guarantees a reference value for the sizing of PV systems in a full self-consumption configuration. Considering working days, the daily trend starts ranging between night-time and daytime, with a slightly higher mean value of 264 and $47 \mathrm{kWh}$ for Store A and B, respectively. Concerning the two stores, referring to the average value of the specific energy intensity, were values of $0.51 \mathrm{kWh} / \mathrm{m}^{2} \mathrm{~d}$ for Store $\mathrm{A}\left(186.1 \mathrm{kWh} / \mathrm{m}^{2} \mathrm{y}\right)$ and $0.27 \mathrm{kWh} / \mathrm{m}^{2}$ day for Store B $\left(98.55 \mathrm{kWh} / \mathrm{m}^{2} \mathrm{y}\right)$. The values are sensibly lower than those available in the literature.

Some general data that can be obtained from the energy consumption profiles of the two stores are summarized in Table 5.

Table 5. Reference data of energy consumption for the two stores under analysis.

\begin{tabular}{ccc}
\hline Parameters & Store A & Store B \\
\hline Gross annual consumption $(\mathrm{MWh})$ & 2959 & 479 \\
Annual average hourly consumption $(\mathrm{kWh})$ & 337 & 54 \\
Maximum daily consumption $(\mathrm{kWh})$ & 13,045 & 1949 \\
Minimum daily consumption $(\mathrm{kWh})$ & 4590 & 785 \\
Holydays average hourly base load $(\mathrm{kWh})$ & 191 & 32 \\
Weekdays average hourly base load $(\mathrm{kWh})$ & 264 & 47 \\
Annual hourly peak consumption $[\mathrm{kWh}]$ & 803 & 106 \\
Annual hourly base load $(\mathrm{kWh})$ & 169 & 27 \\
\hline
\end{tabular}




\section{The n-ZEB Food Store with a PV Plants for Energy Production}

The energy demand of the buildings of residential and public use is a problem widely considered in all the countries. Considering the Italian case, interesting recent studies consider this problem with specific reference to food stores and supermarkets. The energy consumption can be reduced through the optimization of the structure (employing effective use of materials), or using efficient technologies and management strategies for acclimatization, as in [30], or by increasing the use of passive solar design strategies; the building design and architectural features play a relevant role too, defining the passive contribution to heating and cooling, the shading capacity of the building and the amount of natural lighting [31]. Different studies, such as [32], propose the use of advanced poly-generation systems.

The systematic installation of RES on public buildings as commercial ones, will permit us to reduce the use of fossil sources and transmission and distribution losses along the main power grid and contribute to electric peak shaving and partial-loads losses reduction. As a direct consequence, this will lead to a new role for such structures, shifting from a passive energy consumer to active prosumers able to produce energy and distribute energy [33].

In particular, the energy production in buildings of public use and with a relatively high share of electricity consumption can be mainly obtained with the use of solar-based systems, such as PV, for electricity production or solar thermal collectors for hot water production; this process is strictly related to the kind of HVAC system used in the building.

Regardless, the integration of RES, as in particular of the PV plants, though if in general is considered always positive, today has some relevant technical constraints that limit the diffusion of such a practice. PV plants are vital contributors for the future energy transition to a de-carbonized energy system due to the growing role of electricity, both in the supply of alternative fuels and in the final uses. The added advantage of PV lies in its installation flexibility as it can be sited everywhere and, most importantly, on the buildings and developed areas where the actual load is, hence directly contributing to the optimal use of resources. Energy system integration will grow in importance, requiring the services of technologies, such as storage, as key enablers, both at a central and distributed level for flexible consumers. Flexibility at all levels has an increasing relevance: transforming the demand into a provider for optimal use of resources by turning the end users into prime providers of flexibility is a possible answer.

Considering the two different structures analyzed in Section 3, the profitability and size of the PV power systems can be studied with various different objectives and with different constraints; it could be relevant to understand whether it could be possible to use the electrical grid as a buffer or not. On the basis of these parameters, deduced through the analysis and clustering of electrical consumption trends, different sizing strategies have been developed, according to different goals.

The size of the PV plant can be defined with different objectives and methodologies. Some relevant data concerning the operation of the PV system can be defined, according to the description available in [34] for residential buildings.

The total energy used in the store in a reference period considered (for example one year) can be defined as, $E_{T O T}$. The energy imported from the grid, $E_{I M P}$, is the energy corresponding to the periods during which no production of the PV plant is available or if the production is lower than the request. The energy exported to the power grid, $E_{E X P}$, reflects periods of excess energy production or waste if it is not possible to store energy or to sell the excess energy.

The energy produced can be easily compared with the value that was estimated as the product of the annual solar irradiation typical for the specific place at a given exposure, $H_{S N}$, of a balance of system efficiency, $\eta_{B O S}$, taking into account the various electrical losses in the system, and the peak power of the PV plant, $P_{P V}$.

$$
E_{P V}=\left(H_{S N} \cdot \eta_{B O S}\right) \cdot P_{P V}
$$


The maximum production of a PV system expressed in $\mathrm{kWh} / \mathrm{kW}$ in the specific place and the annual solar irradiation is a consequence of the fact that the nominal power of the PV plant is calculated considering a specific solar irradiation of $1000 \mathrm{~W} / \mathrm{m}^{2}$, and an operating temperature of the modules of $25^{\circ} \mathrm{C}$, values referred as Standard Test Conditions (STC).

Considering a PV plant on a building, self-consumption can be defined as the percentage of PV electricity that is consumed locally vs. the overall electricity generated by the particular PV generator. If there is an exceeding amount of electricity produced, there can be three possibilities. It is exported to the grid, if this is permitted by the contract; it can be stored in a battery to be used at later times when the solar electricity is not covering the load demand or finally, wasted, if grid-injection restriction is imposed (for example zero injection restriction). Figure 5 provides the system topology in the two main different cases, when energy export to the grid is possible and when zero-injection restriction are imposed.

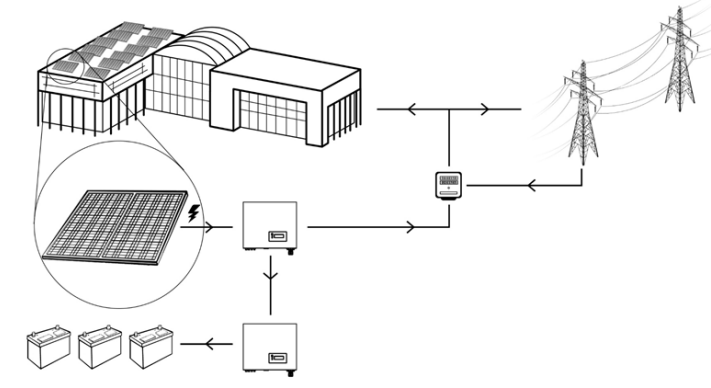

(a)

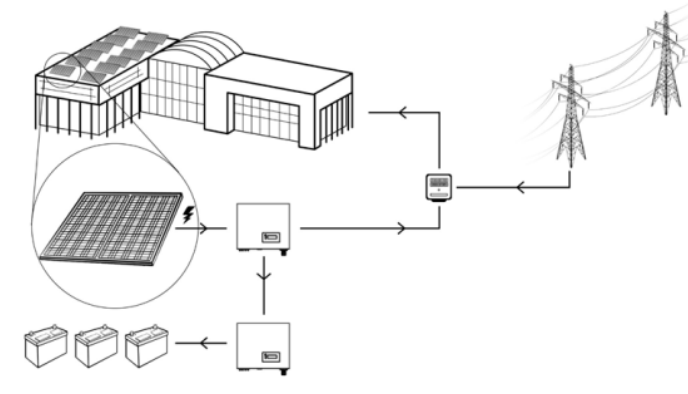

(b)

Figure 5. System components and topology in the cases: without grid injection restriction (a) and with zero-injection restrictions (b).

For each day and each period of the year, using the results of the measurement exposed in the previous sections, it was possible to evaluate the energy exchanged with the power grid to understand how close the system is to the model of a nearly zero-energy building (nZEB) and the amount of energy in excess, that needs to be exported to the grid if possible $E_{E X P}$, (if it is not possible to export energy this amount will be wasted) or imported from the power grid, $E_{I M P}$, can be defined as:

$$
\begin{aligned}
& E_{E X P}=E_{P V}-E_{T O T} \geq 0 \\
& E_{I M P}=E_{T O T}-E_{P V} \geq 0
\end{aligned}
$$

The energy produced with the PV plant and directly used, $E_{D}$, can be calculated by

$$
E_{D}=E_{T O T}-E_{I M P} \geq 0
$$

To quantify the success of the self-consumption strategy, the energy flows directly used and that are imported from or exported to the grid must be exactly defined. To measure the energy produced and directly used in the structure, two specific indicators can be defined. In particular, the self-consumption index, $I_{T O T}$, based on the total energy demand of the building, $E_{T O T}$, and the auto-production index, $I_{P V}$, defined as ratio of the energy directly used and the overall PV production, $E_{P V}$, have been determined and evaluated with the following equation, according to the definition explained in [31]:

$$
\begin{gathered}
I_{T O T}=\frac{E_{D}}{E_{T O T}} \\
I_{P V}=\frac{E_{D}}{E_{P V}}
\end{gathered}
$$


The analysis above considered can be referred to the single day, to the different months of operation or to the whole year.

Concerning the size of the PV plant, different strategies can be identified in order to define it, according to the different objectives as:

- $\quad$ producing the total amount of energy consumed in the summer period (when the PV plant production is sized at maximum level);

- $\quad$ maximizing the $I_{P V}$ index in the perspective of a full self-consumption strategy (PV plant with minimum size);

- $\quad$ obtaining average production level imposing a well-defined amount of energy produced by PV plant (from 40 to $60 \%$ ) with respect to the total energy required (plant of medium to high size);

- $\quad$ maximizing the $I_{T O T}$ index, so obtaining maximum production and minimum energy losses (in this case the use of a storage system is necessary).

In general, in order to pursue a complete self-consumption strategy, the holidays average hourly base load, the annual hourly base load or the minimum daily consumption can be used: in the latter, considering the maximum value of summer daily solar irradiation for the specific zone of interest $\left(7.8 \mathrm{kWh} / \mathrm{m}^{2}\right.$ corresponding to a PV production of $6.3-6.4 \mathrm{kWh}$ for each $\mathrm{kW}$ installed during the summer period). The maximization of the $I_{P V}$ indicator can be obtained with a value of the PV plant power installed of $560 \mathrm{~kW}$ (for Store A) and of $100 \mathrm{~kW}$ (for Store B), respectively.

Considering a sizing strategy based on the whole year, considering average values of production on a yearly basis, the weekdays average hourly base load or the annual average hourly consumption can be considered as reference levels for mean consumption during the year; in the first case, this time compared to the local average solar irradiation (a value of daily solar irradiation of about $4 \mathrm{kWh} / \mathrm{m}^{2}$ can be assumed as an input parameter, corresponding to a PV production of 3.2-3.3 kWh for each $\mathrm{kW}$ installed), a PV plant of about $1650 \mathrm{~kW}$ (for Store A) and a PV plant of peak power about $280 \mathrm{~kW}$ (for Store B) are required.

The corresponding required surface for installing the PV plant can be estimated in dependence of the typical PV technology used: approximately $5.5 \mathrm{~m}^{2}$ for each $\mathrm{kW}$ installed in case of PV plant that uses monocrystalline modules, while the value of $7 \mathrm{~m}^{2}$ for each $\mathrm{kW}$ installed can be considered in case of polycrystalline PV modules.

The gross annual consumption represents another useful benchmark: an average sizing can be based on a share of about $70 \%$ of the total annual energy demand, leading to a PV power installed for case A and B of 1474 and $226 \mathrm{~kW}$, respectively.

In both cases the self-consumption index $\left(I_{P V}\right)$ share of the energy directly used decreases by about 20-30\%, but the self-sufficiency index $\left(I_{T O T}\right)$, based on the share of energy demand covered by on-site production, highly increases, almost doubled.

Table 6 shows the benchmarks used for the system sizing, along with energy produced by PV plant $\left(E_{P V}\right)$ and flows from $\left(E_{I M P}\right)$ and to the grid $\left(E_{E X P}\right)$.

To further optimize the sizing process, the hourly trend of the energy demand of the whole food store needs to be considered. Moreover, in case of impossibility of exporting energy to the grid, the integration of a storage system of appropriate dimensions is necessary. The storage system adds flexibility to the plant and help offset the time gap between production and consumption, in particular, shifting the energy produced from midday hours to the night.

Table 7 summarizes the values achieved in terms of both PV size and ideal size of the storage system, including the total energy stored along the year $\left(E_{S}\right)$. The storage is set at a mean daily PV potential production level, $4 \mathrm{kWh} / \mathrm{kW}$. As it can be seen, starting from complete self-consumption without storage, in both cases the introduction of a battery system allows the PV size to increase by 2.7 times. Even an optimal size, based on a global balance between the two indexes, returns identical values, $91 \%$ of $I_{P V}$ and $72 \%$ of $I_{T O T}$. 
Table 6. PV production data for one year of operation for different self-consumption levels.

\begin{tabular}{|c|c|c|c|c|c|c|c|}
\hline \multirow[b]{2}{*}{ Store } & \multicolumn{3}{|c|}{ Sizing Benchmarks } & \multicolumn{2}{|c|}{$\begin{array}{c}\text { Annual Energy } \\
\text { Flows }\end{array}$} & \multicolumn{2}{|c|}{ Indexes } \\
\hline & $\begin{array}{c}\text { Daily } \\
\text { Demand } \\
(\mathbf{k W h})\end{array}$ & $\begin{array}{c}\text { PV Production at } \\
\text { Design Point } \\
(\mathrm{kWh} / \mathrm{kW})\end{array}$ & $\begin{array}{l}\text { PV Size } \\
(\mathbf{k W})\end{array}$ & $\begin{array}{c}E_{P V} \\
(\mathrm{MWh})\end{array}$ & $\begin{array}{c}E_{E X P} \\
(\mathrm{MWh})\end{array}$ & $\begin{array}{l}I_{P V} \\
(\%)\end{array}$ & $\begin{array}{c}I_{T O T} \\
(\%)\end{array}$ \\
\hline \multirow{3}{*}{$\mathrm{A}$} & 4590 & 6.3 (summer) & 560 & 626.8 & 8.97 & 99 & 21 \\
\hline & 6336 & 3.2 (yearly) & 1650 & 1849.0 & 655.5 & 65 & 40 \\
\hline & 5675 & 3.2 (yearly) & 1474 & 1655.8 & 508.6 & 69 & 39 \\
\hline \multirow{3}{*}{ B } & 785 & 6.4 (summer) & 99 & 117,249 & 2003.0 & 98 & 24 \\
\hline & 1128 & 3.3 (yearly) & 280 & 329,247 & 126,090 & 62 & 42 \\
\hline & 919 & 3.3 (yearly) & 226 & 267,661 & 77,561 & 71 & 40 \\
\hline
\end{tabular}

Table 7. PV production data for full self-consumption based on hourly data analysis (with storage system).

\begin{tabular}{cccccccc}
\hline \multirow{2}{*}{ Store } & \multicolumn{2}{c}{ System Size } & \multicolumn{2}{c}{ Annual Energy Flows } & \multicolumn{2}{c}{ Indexes } \\
\cline { 2 - 8 } & $\begin{array}{c}\mathbf{P V ~ S i z e} \\
\mathbf{( k W )}\end{array}$ & $\begin{array}{c}\text { Storage Size } \\
\mathbf{( k W h )}\end{array}$ & $\begin{array}{c}\boldsymbol{E}_{\boldsymbol{P V}} \\
\mathbf{( M W h )}\end{array}$ & $\begin{array}{c}\boldsymbol{E}_{\boldsymbol{S T}} \\
\mathbf{( M W h )}\end{array}$ & $\begin{array}{c}\boldsymbol{E}_{\boldsymbol{E X P}} \\
\mathbf{( M W h )}\end{array}$ & $\begin{array}{c}\boldsymbol{I}_{\boldsymbol{P V}} \\
\mathbf{( \% )}\end{array}$ & $\begin{array}{c}\boldsymbol{I}_{\boldsymbol{T} O T} \\
\mathbf{( \% )}\end{array}$ \\
\hline \multirow{4}{*}{$\mathrm{A}$} & 480 & - & 539.2 & - & 2.4 & 100 & 18 \\
& 1330 & 5320 & 1494.0 & 384.2 & 7.15 & 100 & 50 \\
& 2100 & 8400 & 2359.0 & 856.0 & 215.9 & 91 & 72 \\
\hline \multirow{3}{*}{$\mathrm{B}$} & 82 & - & 97.1 & - & 0.48 & 100 & 20 \\
& 226 & 880 & 260.6 & 71.2 & 1.08 & 100 & 54 \\
& 320 & 1280 & 379.0 & 133.2 & 34.66 & 91 & 72 \\
\hline
\end{tabular}

This again highlights how the standardization of these kind of structures and their management is a useful point for a general discussion and approach for the integration of RES, with appropriate scaling based on climatic factors and building dimensions.

The graph of Figure 6 shows the daily energy production of three different PV plants disposed on the roof of Store B. The first one is the basic PV plant of peak power $99 \mathrm{~kW}$ without storage, while the second and the third are the plants with peak power of 226 and $320 \mathrm{~kW}$, both equipped with a storage system, as reported in Table 7. In particular, in the figure typical values of energy production profiles of the three plants during summertime (dotted lines) and during winter season are reported, while the bars provided for each hour of the year represent minimum and maximum value of the energy required in the specific hour defined along the whole year.

It is interesting to remark that in all the cases under consideration, the available roof surface of the building is sufficient to contain the modules (the plant of $320 \mathrm{~kW}$ of peak power could require approximately $2300 \mathrm{~m}^{2}$ of surface). Indeed, in the last two cases, some problems can be correlated with the quite high size of the electrochemical storage system, 880 and $1280 \mathrm{kWh}$ capacity, that surely contribute to increase the cost of the plants. The authors have clear in mind that PV plant sizing should be based on economic optimization and different considerations have to be introduced, considering the cost of investment, dependent on the specific cost of PV modules and components and the economic savings returned, but the technical validity of the solution proposed in the present paper and the problems involved can be appreciated based only on energy analysis, considering this the first step of a more complete analysis. 


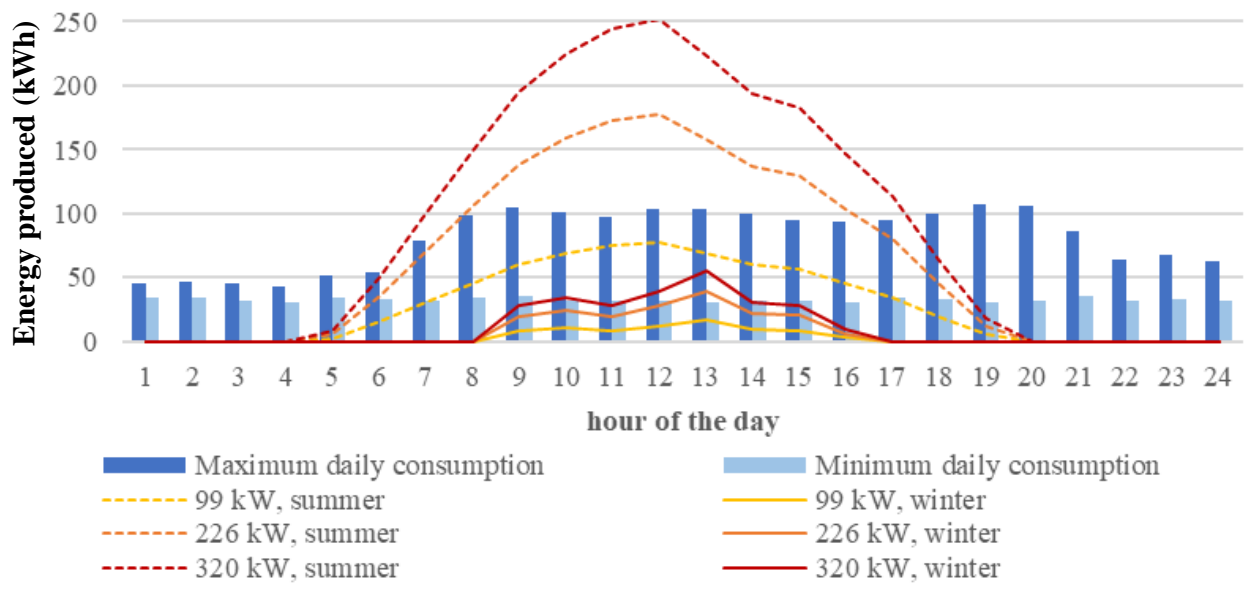

Figure 6. Hourly energy demand and hourly energy production with PV plants of three different sizes, for store B.

\section{Conclusions}

The paper provides the problem of improving the energy performance of food retail stores and supermarkets, based on general analysis and on some real operational data. In particular, the paper has proposed possible strategies for the design of PV plants sized in order to support the energy demand of the various systems providing the various services in the food store. The sizing strategy of PV plants is aimed to maximize the PV plant production and to increase the self-consumption share. Three different objectives for the design are proposed: a plant of reduced size for producing the energy required for the summer period; a plant of quite high size designed for maximizing the self-production of energy during the whole year and finally a plant of medium size for producing a well-defined amount of the energy required for the store (from 40 to $60 \%$ ).

Two different stores, typical of Italian territory, were used for testing the methodology proposed: a quite large store and the typical local store. The first has a total surface of about $20,000 \mathrm{~m}^{2}$ while the second has a total surface of $4830 \mathrm{~m}^{2}$. In the first case the size of the PV plant can range from a minimum value of less than 500 up to $2100 \mathrm{~kW}$, while in the local store, the PV plant size ranges from 80 to $320 \mathrm{~kW}$. In both the cases, the share of the energy produced with the PV plant moved from about 20 up to $70 \%$, if a storage system of relevant size was used. The energy storage could be interesting both to use the energy in excess produced during the day and it can also help with the fluctuating energy supply and demand. In all the cases considered it was possible to use the roof surface of the store for installation of the PV plant.

In general, it appears to be quite easy to define a PV plant that could be able to produce energy for the seasonal peak and covering an amount of the energy required for the whole year in the range between 40 and $60 \%$ of the total yearly energy required.

It appears surely more difficult to pursue the objective of defining the size of the plant according to a totally self-consuming strategy or approaching a level of energy production higher than $80 \%$ of the energy required for the whole year. In this case a relevant oversizing of the plant and the installation of a relevant amount of storage capacity is necessary. This will surely determine an increase in the total cost of the plant, and regardless a relevant part of the energy produced needs to be directed to the grid or wasted. Even if PV plant sizing should be based on economic optimization and in this case the size of the PV system will be directly dependent on the cost of the PV module and grid tariff, the idea of a systematic installations of PV plants to produce energy for food stores and supermarkets appears to be strategic in order to reduce the impact of such structures on the energy grid and to determine a further increase in the diffusion of PV plants integrated on buildings. 
Author Contributions: Conceptualization, A.F. and G.C.; methodology, A.F. and G.C.; software, A.F. and G.C.; validation, A.F. and G.C.; formal analysis, A.F. and G.C.; investigation, A.F. and G.C.; data curation, A.F. and G.C.; writing-original draft preparation, A.F. and G.C.; writing-review and editing, A.F. and G.C.; supervision, A.F. and G.C. All authors have read and agreed to the published version of the manuscript.

Funding: This research received economic support from the University of Pisa with "Fondi di Ateneo 2020".

Institutional Review Board Statement: Not applicable.

Informed Consent Statement: Not applicable.

Data Availability Statement: The data used for this paper will be furnished by the authors if required.

Acknowledgments: The authors wish to thank the technicians of INRES Coop for the constructive discussion about the problem and for the provision of data useful to the present research activity. The authors would like to thank the personal of DESTEC, University of Pisa, for his valid help in the administrative part of the work and for the technical support.

Conflicts of Interest: The authors declare no conflict of interest.

\section{Nomenclature}

$\begin{array}{ll}\text { AHU } & \text { Air Handling Unit } \\ A_{P V} & \text { Total area of PV modules }\left(\mathrm{m}^{2}\right) \\ \text { BIPV } & \text { Building Integrated PhotoVoltaic } \\ \text { BOS } & \text { Balance of system } \\ E_{D} & \text { Electrical energy produced by the PV plant and directly used in the store }(\mathrm{kWh}) \\ E_{E X P} & \text { Electrical energy produced by the PV plant and exported to the grid }(\mathrm{kWh}) \\ E_{I M P} & \text { Electrical energy imported from the grid }(\mathrm{kWh}) \\ E_{P V} & \text { Electricity produced by the PV plant }(\mathrm{kWh}) \\ E_{S} & \text { Energy stored (kWh) } \\ E_{S E L F} & \text { Electrical energy produced by the PV plant and directly used in the house }(\mathrm{kWh}) \\ E_{T O T} & \text { Total electrical energy demand of the building }(\mathrm{kWh}) \\ \mathrm{EI} & \text { Energy Intensity, value referred to one year }\left(\mathrm{kWh} / \mathrm{m}^{2} \mathrm{y}\right) \\ H_{S N} & \text { Reference value of the annual solar irradiation }\left(\mathrm{kWh} / \mathrm{m}^{2}\right) \\ \mathrm{H}_{\mathrm{d}} & \text { Daily solar irradiation }\left(\mathrm{kWh} / \mathrm{m}^{2}\right) \\ \mathrm{HVAC} & \text { Heating Ventilation and Air Conditioning } \\ I_{P V} & \text { Self-consumption percentage of total energy produced by the PV system }(\%) \\ I_{T O T} & \text { Self-consumption percentage of total electrical demand of the building }(\%) \\ \mathrm{n} & \text { Cumulative number of hours of normal distribution } \\ \mathrm{nZEB} & \text { Nearly zero energy building } \\ \mathrm{NZEB} & \text { Net zero energy building } \\ \mathrm{PV} & \text { Photovoltaic } \\ P_{P V} & \text { Peak power of the PV plant referred to the STC }(\mathrm{kW}) \\ \mathrm{RES} & \text { Renewable energy system } \\ \mathrm{RH} & \text { Relative humidity }(\%) \\ \mathrm{STC} & \text { Standard Test Conditions for PV plant sizing } \\ \mathrm{T}_{\mathrm{avg}} & \text { Average value of external temperature } \\ \mathrm{ZEB} & \text { Zero energy building } \\ \eta_{\mathrm{BOS}} & \text { Balance of system efficiency for the PV plant }(\%)\end{array}$

\section{References}

1. Ameen, R.F.M.; Mourshed, M. Urban sustainability assessment framework development: The ranking and weighting of sustainability indicators using analytic hierarchy process. Sustain. Cities Soc. 2019, 44, 356-366. [CrossRef]

2. Tassou, S.A.; Ge, Y.T.; Hadawey, A.; Marriott, D. Energy consumption and conservation in food retailing. Appl. Therm. Eng. 2011, 31, 147-156. [CrossRef]

3. IEA. World Energy Balances and Statistics. World Energy Balance. 2019. Available online: https://www.iea.org/data-andstatistics / data-products (accessed on 8 September 2021).

4. $\quad \mathrm{Wu}$, J.; Lian, Z.; Zheng, Z.; Zhang, H. A method to evaluate building energy consumption based on energy use index of different functional sectors. Sustain. Cities Soc. 2020, 53, 101893. [CrossRef] 
5. Ríos-Fernández, J.C. Economic and environmental improvements using high energy efficiency HVAC in supermarkets. Clean Technol. Environ. Policy 2020, 22, 1417-1429. [CrossRef]

6. Monforti-Ferrario, F.; Dallemand, J.-F.; Pinedo Pascua, I.; Motola, V.; Banja, M.; Scarlat, N.; Medarac, H.; Castellazzi, L.; Labanca, N.; Bertoldi, P.; et al. Energy Use in the EU Food Sector: STATE of Play and Opportunities for Improvement; Publications Office of the European Union: Brussels, Belgium, 2015.

7. Sullivan, R.; Gouldson, A. Ten years of corporate action on climate change: What do we have to show for it? Energy Policy 2013, 60, 733-740. [CrossRef]

8. Rios-Fernandez, J.C.; Roqueñí, N. Analysis of the potential of Spanish supermarkets to contribute to the mitigation of climate change. Sustain. Prod. Consum. 2018, 14, 122-128. [CrossRef]

9. Hasan, A.; Bahadori-Jahromi, A.; Mylona, A.; Ferri, M.; Tahayori, H. Investigating the Potential Impact of Future Climate Change on UK Supermarket Building Performance. Sustainability 2021, 13, 33. [CrossRef]

10. Mylona, Z.; Kolokotroni, M.; Tassou, A.S. Coupling night ventilative and active cooling to reduce energy use in supermarkets with high refrigeration loads. Energy Build. 2018, 171, 26-39. [CrossRef]

11. Ferreira, A.; Duarte Pinheiro, M.; de Brito, J.; Mateus, R. Combined carbon and energy intensity benchmarks for sustainable retail stores. Energy 2018, 165, 877-889. [CrossRef]

12. Acha, S.; Du, Y.; Shah, N. Enhancing energy efficiency in supermarket refrigeration systems through a robust energy performance indicator. Int. J. Refrig. 2016, 64, 40-50. [CrossRef]

13. Franco, A.; Salza, P. Strategies for optimal penetration of intermittent renewables in complex energy systems based on technooperational objectives. Renew. Energy 2011, 36, 743-753. [CrossRef]

14. Antonelli, M.; Desideri, U.; Franco, A. Effects of large scale penetration of renewables: The Italian case in the years 2008-2015. Renew. Sustain. Energy Rev. 2018, 81, 3090-3100. [CrossRef]

15. Saengsikhiao, P.; Taweekun, J.; Maliwan, K.; Sae-Ung, S.; Theppaya, T. Improving Energy Efficiency in the Supermarket by Retrofitting Low E Glass Doors for Open Refrigerated. J. Adv. Res. Appl. Sci. Eng. Technol. 2020, 20, 11-17. [CrossRef]

16. Allouhi, A. Solar PV integration in commercial buildings for self-consumption based on life-cycle economic/environmental multi-objective optimization. J. Clean. Prod. 2020, 270, 122375. [CrossRef]

17. Merei, G.; Moshövel, J.; Magnor, D.; Sauer, D.U. Optimization of self-consumption and techno-economic analysis of PV-battery systems in commercial applications. Appl. Energy 2016, 168, 171-178. [CrossRef]

18. Cho, J.; Kim, Y.; Koo, J.; Park, W. Energy-cost analysis of HVAC system for office buildings: Development of a multiple prediction methodology for HVAC system cost estimation. Energy Build. 2018, 173, 562-576. [CrossRef]

19. McDowall, R. Introduction to HVAC. In Fundamentals of HVAC Systems; McDowall, R., Ed.; Elsevier: Amsterdam, The Netherlands, 2007; Chapter 1; pp. 1-10. ISBN 9780123739988. [CrossRef]

20. Galvez-Martos, J.-L.; Styles, D.; Schoenberger, H. Identified best environmental management practices to improve the energy performance of the retail trade sector in Europe. Energy Policy 2013, 63, 982-994. [CrossRef]

21. Mylona, Z.; Kolokotroni, M.; Tassou, S.A. Frozen food retail: Measuring and modelling energy use and space environmental systems in an operational supermarket. Energy Build. 2017, 144, 129-143. [CrossRef]

22. Mylona, Z.; Kolokotroni, M.; Tassou, S.A. A study of improving energy efficiency of small supermarkets by modelling interaction between building, HVAC, refrigeration and display product. In Proceedings of the 5th IIR Conference on Sustainability and the Cold Chain, Beijing, China, 5-8 April 2018; Available online: https://bura.brunel.ac.uk/bitstream/2438/16100/1/FullText.pdf (accessed on 23 August 2021).

23. Van Der, S.S.; Lindberg, U.; Lane, A.-L.; Arias, J. Performance indicators for energy efficient supermarket buildings. In Proceedings of the 24th IIR International Congress of Refrigeration, ICR 2015, Yokohama, Japan, 16-22 August 2015. [CrossRef]

24. Foster, A.; Evans, J.; Maidment, G. Benchmarking of supermarket energy consumption. In Proceedings of the 5th IIR Conference on Sustainability and the Cold Chain, Beijing, China, 5-8 April 2018; Available online: https:/ /openresearch.lsbu.ac.uk/item/86v68 (accessed on 23 August 2021). [CrossRef]

25. Foster, A.; Brown, T.; Evans, J.; Maidament, G. Relationship between specific energy consumption and size of supermarket stores. In Proceedings of the 25th IIR International Congress of Refrigeration, Montreal, QC, Canada, 24-30 August 2019; pp. 4973-4980. Available online: https:/ / openresearch.lsbu.ac.uk/item/8v1z8 (accessed on 23 August 2021).

26. Hill, F.; Edwards, R.; Levermore, G. Influence of display cabinet cooling on performance of supermarket buildings. Build. Serv. Eng. Res. Technol. 2014, 35, 170-181. [CrossRef]

27. Davidson, C.; Gagnon, P.; Denholm, P.; Margolis, R. Nationwide Analysis of U.S. Commercial Building Solar Photovoltaic (PV) Breakeven Conditions; Technical Report NREL/TP-6A20-64793; National Renewable Energy Laboratory: Denver, FL, USA, 2015. [CrossRef]

28. Willborn, S.; Hesse, A.; Balse, A.; Luh, A. Study on the Profitability of Commercial Self-Consumption Solar Installations in Germany, München; REC Solar Germany GmbH: Munich, Germany, 2014.

29. Zhang, H.; Davigny, A.; Sprooten, J.; Robyns, B.; Colas, F.; Poste, Y. Energy Management Strategy for Commercial Buildings Integrating PV and Storage Systems. Smart Innov. Syst. Technol. 2012, 12, 177-190. [CrossRef]

30. d'Ambrosio Alfano, F.R.; Dell'Isola, M.; Ficco, G.; Palella, B.I.; Riccio, G.; Frattolillo, A. Thermal comfort in Supermarket's refrigerated areas: An integrated survey in central Italy. Build. Environ. 2019, 166, 106410. [CrossRef] 
31. Cillari, G.; Fantozzi, F.; Franco, A. Passive Solar Solutions for Buildings: Criteria and Guidelines for a Synergistic Design. Appl. Sci. 2021, 11, 376. [CrossRef]

32. Catrini, P.; Curto, D.; Franzitta, V.; Cardona, F. Improving energy efficiency of commercial buildings by Combined Heat Cooling and Power plants. Sustain. Cities Soc. 2020, 60, 102157. [CrossRef]

33. Fichera, A.; Marrasso, E.; Sasso, M.; Volpe, R. Energy, Environmental and Economic Performance of an Urban Community Hybrid Distributed Energy System. Energies 2020, 13, 2545. [CrossRef]

34. Franco, A.; Fantozzi, F. Optimal Sizing of Solar-Assisted Heat Pump Systems for Residential Buildings. Buildings 2020, $10,175$. [CrossRef] 